April 2--3, sponsored by the U.S. Air Foree Cambridge Research Center and under the chairmanship of Dr. J. R. O'Connor. 'The U.S. Air Force Cambridge Research Center has for some time been the principal agency engaged on the task of initiating, supporting and co-ordinating a comprehensive research programme on silicon carbide, covering fundamentals and devices on a long-term basis. Forty-six papers were presented, dealing with such matters as the phase relations of the silicon-carbon system, methods of crystal preparation (by sublimation, gaseous cracking, epitaxial growth and from solution), silicon carbide as a solid (crystal strueture, surfact) morphology, oxidation), silicon carbide as a semiconductor (band structure, electrical and optical properties) and silicon carbide devices.

Recent phase studies show that silicon carbide doos not decompose thermally below $2,830^{\circ} \mathrm{C}$., contrary to earlier reports. Large single erystals of the material have, of course, been available for a long time; but, as a rule, these appear only accidentally in the course of manufacture of silicon carbide in large furnaces which do not permit accurate control. In comparison, the laboratory methods listed above lead to crystals of much higher purity (for example, as assessed by neutron activation and spectrographic methods) but of very much smaller size. It has been widely suggester that the scale of the operation may have an important influence on the outcome and that, in any event, the temperature gradient in the direction of growth should be brought under control. Crystal growth from solutions of silicon or ironsilicon alloys supersaturated with carbon has yielded plates up to $8 \mathrm{~mm}$. across and $0.5 \mathrm{~mm}$. thick. The optimum growth conditions have not yet been determined. The structural studies are, of course, devoted to the well-known property of silicon carbide of forming a great variety of polytypes which are not yet fully understood. There is as yet no evidence of any definite connexion between polytype formation and impurity content, but interesting relationships are known to exist between the polytypic structure and the geometry of the spiral growth surfaces,

The width of the forbidden energy gap, derived from optical absorption measurements, has been found to be $2.86 \mathrm{eV}$. at $300^{\circ} \mathrm{K}$., with a temperature coefficient of $-3.3 \times 10^{-4} \mathrm{eV}$. deg. C. The existence of impurity bands has been inferred from observations of electroluminescent spectra as a function of temperature and current density. The electroluminescence itself is now firmly believed to be due to the injection of minority carriers through $p-n$ junctions and their subsequent recombination in luminescent centres, even though many details still remain to be clarified. An electron mobility of $32 \mathrm{~cm} .^{2} /$ volt-sec. has been quoted for material containing $10^{15}$ to $10^{17}$ donors $/ \mathrm{cm}^{3}$.

The question of departures from stoichiometry is still highly controversial. It is not yet known whether such departures exist to any significant extent and whether they lead to donor or acceptor formation if they do. The minority carrier lifetime, measured by observing the photoconductive decay following the cessation of an optical stimulus, is very short but can reach a few tenths of a mierosecond. This fact, coupled with the relatively small carrier mobility, makes the design of silicon carbide transistors a problematical prospect. It is, however, believed that such transistors, whether unipolar or hipolar, could now be made if the best available crystals were used in conjunction with the most sophisticated micromanipulation techniques. In practice, gallium phosphide, with its lower meltingpoint $\left(\sim 1,340^{\circ}\right.$ C. $)$, wide band gap $(2 \cdot 25 \mathrm{\Theta V}$.$) and$ higher carrier mobilities may prove to be an important competitor. Apart from this, there are fair prospects for device applications in the field of high-tem. perature rectification. $p-n$ junctions can be prepared. by the usual doping techniques and a finished encapsulated rectifier capable of operation at $500^{\circ} \mathrm{C}$. was described. The more familiar application of silicon carbide for the manufacture of non-linear current devices ('varistors') is still of great interest. The behaviour of these devices is now reasonably well understood, even though the detailed cireumstances may be complicated by thermal effects, impact ionization and the current-dependent charges in intergranular surface states.

The proceedings of the conference were summarized by a review panel under the chairmanship of Dr. W. Shockley. They will be published in book form by Pergamon Press.

H. K. Henisch

\title{
AVAILABILITY OF PLANT NUTRIENTS
}

MEETING of the British Society of Soil Science
held, by kind permission, at the London School
of Economics on April 9, was devoted to considera-
tion of the factors which determine the availability
of nutrients in the soil. Five papers were presented
and discussed.
Dr. R. K. Schofield (University of Oxford) referred
to the successive stages in transfer of nutrients from
the soil surfaces, through solution to the roots
where metabolic assimilation takes over; any one
stage may provide a limiting factor in the supply
to the plant and the problem is to unravel their
relative importance. Extraction with a weak
electrolyte such as calcium chloride goes some way
towards characterizing the intensity factor of phos-
phorus in the soil, but use of phosphorus-32 and
calcium- 45 has given a better understanding of the labile pool of these nutrients and a measure of the capacity factor. The low concentration of phosphorus extracted by calcium chloride compared with the amount isotopically exchangeable suggests that the time of transit between absorption sites is small. Uptake by roots introduces another factor, but pot experiments with cabbages, barley and lupins using phosphorus-32 showed no differences in the supplies accessible to these plants. Judged by the specific activity of the phosphorus in the plants and in various soil extracts, calcium chloride solution or water gave a better assessment of availability than did many of the solutions often used in soil analysis; these liberated phosphorus which was not available to plants.

Dr. P. Newbould (University of Oxford) described experiments with calcium-45 uniformly mixed with 
two soils in pots. The specific activity of calcium absorbed by barley and ryegrass fell steadily during growth owing to a slow equilibration with forms of calcium other than exchangeable calcium. As roots locally depleted supplies of labile calcium, more calcium came into circulation. Exchangeable and available calcium can no longer be regarded as synonymous, and the latter is affected by the activities of plant roots.

Dr. R. Scott Russell (Agricultural Research Council Radiobiological Laboratory) directed attention to different steps in nutrient absorption by roots and stressed that the effective area of absorption was restricted to a region near the apices. The availability of a nutrient to a plant may be influenced by interactions with other ions either by competition or by physiological changes. Dr. Seott Russell referred to work which suggested that the individual root-absorption characteristics of different crops influenced the apparent availability of a nutrient such as phosphorus in a soil.

The probable parts played by micro-organisms were described by Mr. J. S. Waid (Levington Research Station, Ipswich), who stressed that much of the evidence was circumstantial and required further substantiation. Organisms are known to be able to increase the water solubility of nutrients by oxidation or reduction, and by the decomposition of organic materials; the availability of nitrogen is intimately bound up with biological processes. Soil organisms may compete with roots for soluble nutrients especially when stimulated by supplies of organic materials, some of which may be provided by the roots themselves; production of carbon dioxide or toxins may affect the physiological activity of plant roots.

Dr. G. W. Cooke's paper (Rothamsted Experimental Station) described the problems of assessing the nutrient status of a soil for advisory purposes : here the criterion is the probable economic response of various crops to fertilizer dressings, and in this field soil analysis has not made much progress. The results generally distinguish between the broad levels of nutrient status for phosphorus and potassium, but in order to avoid crop failure in the exceptional cases the overall application of these fertilizers is about double the amount that is economically justified. The assessment of the nitrogen status of soils is even more uncertain, and there is an acute need for the development of fresh analytical techniques tested against field trials. Dr. Cooke suggested that a more successful approach might lie in the use of soil analysis for 'fertility control' whereby a record was maintained of the fertility status of a soil so that warning was given of abnormalities before they became acute.

In the open discussion which followed these papers the following points were among those made.

Correlation between soil analyses and field responses is poorer in tropical and other under-developed areas than it is in Britain, yet the need for reliable soil tests is even greater. Different speakers stressed the importance of studying the anomalous soils in order to discover which factors affecting the availability of nutrients have been neglected. Analysis should not be divorced from examination of profiles since often these showed some physical property which meant that, while nutrients might be available in the chemical sense, they were inaccessible to plant. roots.

The value of plant analysis in relation to fruit crops and forestry was mentioned; by this means it may be easier to recognize an interaction effect which is not revealed by soil analysis. Some progress was also reported on the development of techniques for determining the nitrogen status of soils: this seems to be greatly affected by re-wetting of air-dry samples.
D. V. CrawFord

\section{AHMEDABAD MILLOWNERS' TEXTILE INDUSTRY'S RESEARCH ASSOCIATION}

A TEXTILE research laboratory, created and sustained by the co-operative effort of the industry and the Government of India, was envisaged by the Ahmedabad Millowners' Association as early as 1944. In 1947, the Ahmedabad Textile Industry's Research Association was registered with a membership of seventy-one mills. Ahmedabad thus became the proud pioneer in establishing a co-operative research centre for the cotton textile industry in India.

The Association started functioning in 1949, and its impact was soon felt by the industry in and around Ahmedabad. It became clear to the original members that the benefits accruing from research could with advantage be placed at the disposal of the industry on a nation-wide basis. With this object in view, the constitution of the Association was suitably amended so that mills outside Ahmedabad could become members and enjoy the same research benefits as the original founders. The present strength of members including all categories stands at eighty-eight mills and allied concerns, comprising thirty lakhs of spindles and sixty-three thousand looms-roughly one-third of the Indian cotton textile industry.

The policies of the Association are decided by an autonomous body known as the Council of Adminis- tration. At present, the twenty-member Council is made up of representatives of management, nominees of the Government of India, the director and secretary of the Association as well as directors of other research organizations, and co-opted scientists. The Textile Commissioner is one of the nominees of the Government of India. Shri Kasturbhai Lalbhai has been the chairman of the Council from its inception.

The composition of the Council ensures a balanced and co-ordinated research policy which takes into account similar efforts by other textile research institutions and national laboratories. Further links with Government and with national research in related spheres have been established through the Ministry of Scientific Research and Cultural Affairs.

The Association began modestly in 1949 in three rooms in the Mafatlal Gazalbhai Science Institute. The foundation stone of the present building, which is housed on a 50-acre campus to the west of Gujarat University, was laid by Sardar Vallabhbhai Patel in November 1950 . The building was completed towards the end of 1953 and formally declared open by Shri Jawaharlal Nehru in April 1954. 